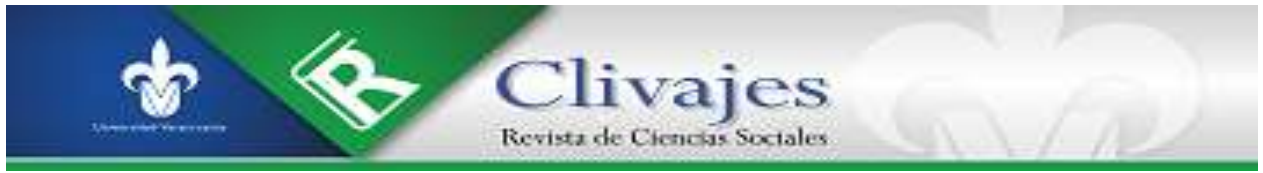

José Alfredo Zavaleta Betancourt

LAHIRE, BERNARD (2016). EN DEFENSA DE LA SOCIOLOGÍA

Clivajes. Revista de Ciencias Sociales. Año VI, número 12, julio-diciembre 2019, pp. 171-174.

http://clivajes.uv.mx/index.php/Clivajes/editor/proofGalley/2587/4455 Instituto de Investigaciones Histórico-Sociales, Universidad Veracruzana

Clivajes. Revista de Ciencias Sociales/ISSN: 2395-9495/IIH-S, UV/Xalapa, Veracruz, México.

Recibido: 04/09/2019

Aceptado: 15/09/2019

Publicación: 21/11/2019 


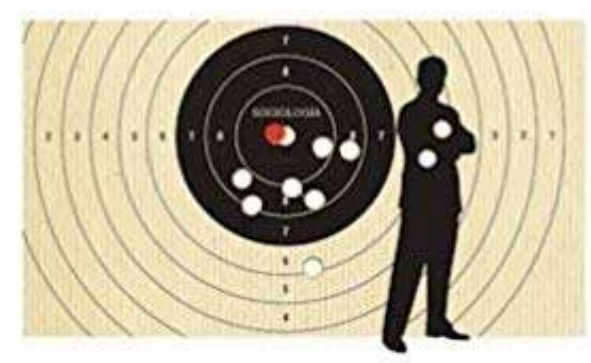

EN DEFENSA DE LA SOCIOLOGÍA

contra el mito de que los sociologos son unos charlatanes, justifican a los deincuentes y distorsionan la realidad

\section{bernard lahire}

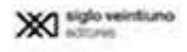

José Alfredo Zavaleta Betancourt IIH-S, UV

Es posible que entre el apoyo a los chalecos amarillos, el rechazo a la pena de muerte, la petición de libertad para Josu Urrutikoetxea y "La defensa de la sociología” haya un vaso comunicante.

Allende la tendencia a interrogarse acerca de la utilidad de la sociología -tendencia encabezada por Dubet (2012): ¿Para qué sirve realmente un sociólogo?, ${ }^{1}$ seguido por Bauman (2014): ¿Para qué sirve realmente...? un sociólogo-, ${ }^{2}$

\footnotetext{
${ }^{1}$ Dubet, F. (2012). ¿Para qué sirve realmente un sociólogo? Buenos Aires, Argentina: Siglo XXI Editores. $136 \mathrm{pp}$.

2 Bauman, Zygmunt. 2014. ¿Para qué sirve realmente...? un sociólogo. Madrid: Paidós. 160 pp.
}

Bernard Lahire (2016), que diez años atrás se ocupó del tema: ¿Para qué sirve la sociología?, ${ }^{3}$ y propuso la integración de la sociología experimental y social, emprende ahora la defensa de nuestra disciplina, mediante una estrategia de comprensión de los ataques políticos "recurrentes" de quienes la consideran parte de una "cultura de la excusa".

Esta estrategia discursiva supera el posicionamiento que acepta el deber de explicarle al público lo que un sociólogo hace por la convivencia social, en defensa activa de quien comparte aquello que Bourdieu solía rechazar de los peligros económicos y políticos de la ciencia para recordarnos las contribuciones de la sociología: historizar, contextualizar, relacionar las prácticas sociales de los individuos, considerados agentes.

En efecto, en su defensa de la sociología, tanto Bourdieu como Wallerstein procedían situando el valor de las ciencias sociales. Lahire opera de forma distinta, se alía a "todos aquellos y aquellas que con calma y sin reposo intentan comprender, incluso en épocas de borrascas”.

De acuerdo a Lahire, hay un ataque neoliberal sistemático contra la sociología, acusada de negar las responsabilidades individuales, la

\footnotetext{
${ }^{3}$ Lahire, B. (2006). ¿Para qué sirve la sociología? Buenos Aires, Argentina: Siglo XXI Editores. 208 pp.
} 
dignidad de las personas, estadísticamente clasificadas, y la libertad de elegir contra las adversidades, lo que se condensa en un libro que considera paradigmático: El malestar en la incultura, de Philippe Val, exdirector de Charlie Ebdo y France Inter, publicado en Francia en 2015.

En defensa de la sociología de Bernard Lahire, publicado en 2016, hace pedazos, deconstruye, anula los argumentos de quienes comparten la idea de que la sociología es responsable de la ineptitud de los individuos, al oponer la idea de la lógica de las prácticas sociales a la idea ingenua de la libertad exenta de constricciones.

Lahire disecciona, reflexiva y metódicamente, ese posicionamiento conservador, esa disposición no disciplinaria basada en ocurrencias, recordando que detrás de la condena a la sociología subyace una incultura del malestar, como si el título del libro de Val fuese un reflejo inverso de lo que la sociología hace, mientras los políticos, periodistas y abogados neoliberales lo ignoran. Así, a la ficción o "robinsonada" de un individuo o sujeto aislado, insular, opone la idea del actor plural, construido a través de las múltiples constricciones que ha experimentado durante su vida, como un pasado incorporado mediante una perspectiva sociológica a escala individual. Afirma
Lahire (2016): "La singularidad relativa de cada individuo no es más que la síntesis o la sutil combinación del conjunto de experiencias vividas junto con los demás en grados de intensidad variables y en un orden determinado... indisociable de los grupos e instituciones que frecuenta y los tipos de interacción en los cuales se vio involucrado" (p. 420).

El autor somete a critica el sentido común neoliberal, según el cual el crimen es responsabilidad del criminal, sin interrogarse acerca de su trayectoria social, o bien, que el fracaso escolar es responsabilidad de los estudiantes que han fracasado, mientras recuerda la paradoja que comete $\mathrm{Val}$ cuando señala que la sociología es "dominante", pero todos sus discursos defienden un posicionamiento por los dominados.

De acuerdo a Lahire, que en esto sigue a Bourdieu - precisamente Val (cit. por Lahire) considera responsable a este último de la amplia presencia de la sociología como sociologismo y cultura de la excusa. Dice: "su origen puede buscarse en el centro de la corriente dominante de la sociología francesa, sobre la que reina Pierre Bourdieu desde lo alto del Collège de France" -, los críticos de la sociología, que en El malestar ignoran lo que esta disciplina hace, confunden el juzgar con el 
comprender para movilizar "las fuerzas de la represión contra las fuerzas del entender".

Recomienda Lahire, recuperando la fórmula de Spinoza esgrimida por Bourdieu: "no reír, no llorar y no odiar, sino entender", como respuesta contundente a quienes pretenden juzgar sin interdicciones o descripciones de sus actos, cual si fuesen elecciones libres de constricción: "querrían poder juzgar (e incluso castigar sin explicaciones ni reproches)", señala Lahire y añade: "confunden dos planos profundamente distintos: por un lado, el primer plano, no normativo, propio del conocimiento científico, y por el otro, el segundo plano, normativo, propio de la justicia, la policía, la cárcel” (pp. 2016, 267).

Esta defensa, orientada por el principio de que las ciencias sociales, y particularmente la sociología, deben "defenderse cada vez que es posible" antepone la idea del entendimiento de lo social a escala individual para reducir la exclusión o evitar la destrucción de los “otros" y, por eso, se opone a la reducción de la ciencia al derecho. Por lo mismo, Lahire reprocha a Philippe Val que no piense en las múltiples constricciones sociales que pesan sobre los pobres, dominados, estigmatizados o excluidos, o que ignore cómo se configura una elección bajo coacción, mientras aquél, desde las élites, defiende, como "naturales", el talento, la desigualdad, la dominación. En el fondo, dice Lahire: es la historia una y otra vez contada de quien "tiene interés en hacer pasar conejo por liebre".

Lahire, Bernard, (2016). En defensa de la sociología. Buenos Aires, Argentina: Siglo XXI Editores. 128 pp. 